\title{
O CORPO QUE HABITO: DESAFIOS DE GESTANTES TRANSEXUAIS NO ACESSO DIGNO À SAÚDE
}

\section{THE BODY I HABIT: CHALLENGES OF TRANSEXUAL PREGNANT PEOPLE IN THE ACCESS WHICH WILL BE DECENT}

Quize Cristina Silva Rôla*

Bárbara Raíssa de Oliveira**

\begin{abstract}
RESUMO: O presente texto tem o propósito de refletir o que a doutrina discute sobre o acesso à saúde de gestantes transexuais. Com este fim, foi realizada uma busca em base de dados de saúde e jurídica. Para a análise dos dados obtidos na revisão de literatura, foi utilizado o método descritivo, retratando as características do objeto de estudo e possíveis respostas ao problema.
\end{abstract}

PALAVRAS-CHAVE: acesso à saúde; direito à saúde; humanização

ABSTRACT: The presente text has the purpose of reflecting what the doctrine discusses on the access to health of transsexul pregnant for this purpose, a search was carried out in a health and legal database. For the analysis of the data obtained in the literature review, the descriptive method was used, portraying the characteristics of the object of study and possible responses to the problem.

KEYWORDS: acess to health; humanization; right to health

\section{INTRODUÇÃO}

O direito à saúde é direito fundamental e se encontra positivado pela Constituição de 1988, em seu art. 6 e art. 196. Esse instituto jurídico de cunho social é referenciado, novamente, na disciplina constitucional quando o legislador tratou do cálculo do salário mínimo, no art. 7, IV, tendo em vista que se este não for capaz de proporcionar a satisfação da necessidade de uma saúde básica, não corresponderá ao seu fim social e constitucional.

\footnotetext{
* Graduanda em Direito na UFBA. Especialista em Direito Médico. Especialista em Fisioterapia em Terapia Intensiva Adulto. Preceptora da Residência de Fisioterapia em Unidade de Terapia Intensiva e Emergência Adulto do Hospital Geral Roberto Santos (SESAB), Coordenadora do Núcleo de Educaçãopermanente multiprofissional do HGRS.

** Graduanda em Direito na UFBA. Estagiária no TJBA. Membro do CEPEJ. Integrante do grupo de estudos 'acesso à justiça"
} 
A competência para os cuidados da saúde foi considerada como comum entre os entes federados (União, Estados-membros, Distrito Federal e Municípios), de modo que, por força do art. 23, II da CRFB/88, assim como, do art. 30, VII, todos os níveis da unidade federativa se encontram igualmente obrigados a proporcionar esse direito social à população.

Como a saúde está diretamente relacionada à dignidade humana, o Estado tratou de buscar conferir uma aplicação social mais ampla quanto fosse possível, através da criação do Sistema Único de Saúde (SUS), matéria assegurada na Carta Magna, objetivando garantir a todas as pessoas, e principalmente para a população hipossuficiente (como se infere do art. 199 da CRFB/88), um livre acesso aos serviços públicos.

Em contrapartida, é sabido que o direito positivado não garante, de pronto, sua eficácia social. O acesso à saúde, no Brasil, encontra óbices de ordem material e imaterial, como falta de infraestrutura nos postos de atendimento, mão-de-obra qualificada em termos técnicos e no sentido de aptidão para conferir um tratamento humanizado, independente de gênero, classe, raça, orientação sexual ou credo, bem como ausência de vontade política dos governantes para garantir uma boa execução dos serviços públicos.

Convém explicitar que identidade de gênero diz respeito à forma como cada pessoa se sente, se do gênero feminino ou masculino, independente do sexo biológico, ou seja, aquele designado no momento do seu nascimento. De acordo Scott (1990), gênero constitui um elemento das relações sociais baseadas nas diferenças deduzidas entre os sexos e é o primeiro campo no qual o poder se articula.

Neste sentido, salienta-se que mulheres trans são aquelas que, em decorrência da genitália (ter um pênis), foi denominada homem ao nascer, mas se identifica como mulher. Já homens trans são aqueles que, em função da genitália (ter uma vagina) foi denominado mulher ao nascer, mas se reconhece enquanto um homem. Sendo assim, pessoas cis são aquelas que se identificam com o gênero que lhe foi imputado no momento do seu nascimento.

Diante desse panorama, interessa fazer uma breve análise sobre o acesso à saúde das pessoas transexuais durante o período de gestação e suas experiências 
de acolhimento pelos profissionais. O objetivo é analisar as estratégias de inclusão adotadas pelos serviços de saúde no tocante à recepção de homens trans grávidos e as demais questões envolvidas no tema.

\section{O BIOPODER E A TRANSEXUALIDADE}

No século XVIII começa a surgir com mais força, a medicina hospitalar retirando do hospital a ideia de caridade, com foco nos religiosos, para o que chamamos hoje de saber biomédico. Embora possa parecer uma relação direta, o poder que o médico detém hoje, no século XXI, com uma sociedade hospitalocêntrica, não adveio da ciência, mas da disciplina, como traz Foucault (1998).O poder disciplinar requer vigilância permanente e classificatória, que permite distribuir os indivíduos, julgá-los, medi-los, localizá-los e, por conseguinte, utilizá-los ao máximo (FOUCAULT, 1998).

Desse modo, o corpo masculino trans, quando experiencia a gestação, confronta-se com o ápice do estereótipo feminino, revelando a dificuldade em relação a maneira como as sociedades lidam com a percepção dos corpos humanos e com as consequências disso, sendo assim, estabelecendo arranjos que são mutáveis frente às novas situações criadas pelas práticas humanas (GOMES, 2008).

Nesse contexto, o poder disciplinar se veste de ciência para guiar, controlar, é um poder sobre a vida. Caracterizar um indivíduo no binômio saúde/doença é a chave para controlar as pessoas que se identificam como transexuais porque dentro do conceito estabelecido de saúde não é possível existir sofrimento e é necessário que a equipe de saúde identifique essa dor, para só então possibilitar a modificação no corpo (PORCHAT e OFSIANY, 2020).

A partir da constatação, advinda da psiquiatria que classifica a disforia de gênero como um Transtorno do Desenvolvimento Sexual foi possível a intervenção física, a fim de transpor o sofrimento psíquico tornando possível o uso do nome social, da hormonioterapia e acesso à cirurgia de adequação do corpo à identidade de gênero e social (MARQUES; LAVINAS e MULLER, 2018), ou seja, no desejo de mudança, a autonomia do paciente não é considerada, dando luz apenas ao detentor do poder. 
Embora em um primeiro olhar, a possibilidade de realizar a cirurgia tenha sido um passo importante, deixar a decisão sob a égide do profissional de saúde é extirpar a autonomia dos indivíduos. O relatório de Belmont, promulgado em 1978, trouxe discussões sobre ética em pesquisa quando se refere ao respeito às pessoas, infere que "uma pessoa autônoma é capaz de deliberar acerca de suas metas pessoais e atuar no sentido de suas deliberações".

Contudo, esse discurso trazido do eixo biomédico permeia com tal força na sociedade e o discurso jurídico está envolto nesse contexto, haja vista, que na nossa legislação, é possível verificar esse diálogo, como no art. 13 do código civil que determina que "salvo por exigência médica, é defeso o ato de disposição do próprio corpo, quando importar diminuição permanente da integridade física, ou contrariar os bons costumes". A leitura do texto legal traz algumas reflexões em torno da real preocupação do legislador, diante do termo "contrariar bons costumes".

Para Freitas (2016), essa limitação se coaduna com o respeito à Dignidade da Pessoa Humana, existindo "uma autovinculação do próprio titular do Direito à Integridade Física ao preceito da Dignidade da Pessoa Humana, motivo pelo qual ninguém pode renunciar à própria dignidade".

Sob essa perspectiva e sob a luz do Direito Penal, o médico estaria cometendo uma conduta típica. Freitas (2016) pondera também, que a dignidade "confere autonomia ou margem de liberdade dispositiva, pois, caso contrário, estaríamos escravizando o titular em seu próprio direito",

Dessa maneira, faz-se necessário realizar uma ponderação entre a Dignidade irrenunciável e a autodeterminação do titular do Direito e assim encontrar a "justa medida de disponibilidade da incolumidade física do Ser Humano”. Diante disso, não ficaríamos refém do poder social estabelecido.

\section{ACESSO À SAÚDE DA POPULAÇÃO TRANSEXUAL}

Como se sabe, a Lei Maior é conhecida como a Constituição Cidadã e foi fruto de um processo constituinte, que representou o momento luminoso da história 
republicana brasileira mais recente, uma vez que tinha terminado o período ditatorial, após 20 anos de violações aos direitos fundamentais.

Os cidadãos(as) brasileiros(as) participaram ativamente do processo de redemocratização através das emendas populares, que contaram com milhões de signatários e expressavam as aspirações do povo no tocante aos mais variados temas essenciais à uma existência digna, inclusive, o da saúde pública - um dos eixos temáticos do presente trabalho.

A temática da saúde veio a integrar o texto constitucional, em seu art. 196: "A saúde é direito de todos e dever do Estado, garantido mediante políticas sociais e econômicas que visem à redução do risco de doença e de outros agravos", além disso, garante "acesso universal e igualitário às ações e serviços para sua promoção, proteção e recuperação."

Desse modo, a partir 1988, com a Carta Política, o acesso à saúde foi universalizado no Brasil, uma vez que foi inaugurado o SUS, com vistas a atender não só os trabalhadores vinculados à Previdência Social, mas à toda população. O referido sistema é considerado uma vitória do movimento sanitarista na Assembleia Constituinte de 1987.

Vale menção, também, os artigos 197 e 198 da CF/88, bem como as seguintes legislações sobre o SUS: Leis n. $\underline{8.080 / 90}, \underline{8.142 / 90}$, Lei Complementar 141/2012, e no Decreto 7.508/11. Além dessas, há um outro documento a respeito do SUS, que traça os direitos e deveres dos cidadãos(as) relacionados à saúde pública no Brasil, a Carta dos Direitos dos Usuários da Saúde.

A supracitada Carta, aprovada no Conselho Nacional de Saúde, em 2009, e publicada na Portaria $n . \stackrel{0}{1.820}$, do mesmo ano, dentre outros princípios, preceitua que todo cidadão tem direito ao acesso ordenado e organizado aos sistemas de saúde, a tratamento adequado e efetivo para seu problema e ao atendimento humanizado, acolhedor e livre de qualquer discriminação.

Por sua vez, em termos práticos, observa-se uma limitação, de ordens material e imaterial, no que concerne à assistência à saúde da população. Sobre as dificuldades de ordem estrutural, pode-se utilizar como exemplo a insuficiência de 
recursos direcionados ao SUS, em 2020, um ano de enfrentamento da pandemia de coronavírus.

Segundo o Instituto de Estudos Socioeconômicos, o Inesc em 2020, 0 orçamento do Ministério da Saúde, em 2019, correspondeu a $R$ \$ 138, 4 bilhões, representando um tímido crescimento de $0,9 \%$ em relação ao ano anterior. Tal estagnação parece ter íntima relação com a EC 95/2016, que determinou um teto de gastos públicos.

Além disso, o estudo divulgado pelo Inesc alerta para uma execução orçamentária, na saúde, aquém dos valores autorizados, de 2012 a 2019, o que aponta para uma postura inerte do Poder Público diante das demandas da sociedade. Por seu turno, quanto às questões deficitárias de ordem imaterial, na área da saúde, cabe citar a escassez de profissionais que, além da formação técnica necessária para o exercício das suas atividades, disponham de uma visão humanizada sobre o atendimento aos (às) pacientes.

Importa destacar que, muito embora, a Magna-Carta, em seu artigo 5, estabeleça uma igualdade formal entre as cidadãs e os cidadãos brasileiros(as), esta relação equânime não se reflete no plano prático.

É sabido que os índices de desigualdade no Brasil são elevados e agravados pelo modelo de desenvolvimento econômico adotado pelo Estado, que opera sob uma lógica de maximização dos lucros, em que um seleto grupo social, concentrador de renda, explora a mão-de-obra de toda uma coletividade, cujos ganhos malmente garantem a sua sobrevivência (HARVEY, 2016).

Dessa forma, uma expressiva parcela da população brasileira depende dos serviços públicos para sobreviver, seja na área da saúde, como na educação, transporte, dentre outras.

Segundo o site UOL, o Instituto Brasileiro de Geografia e Estatística divulgou dados da Pesquisa Nacional da Saúde, referentes ao ano de 2019, anterior à pandemia de covid-19, que indicam que $71,5 \%$ dos brasileiros(as) são dependentes do SUS e que existe uma relação direta entre a raça e o nível de instrução e a cobertura de plano de saúde, destacando que as pessoas brancas ou com ensino superior seriam aquelas mais propensas a possuírem essa cobertura. 
Sendo assim, pode-se concluir que, se o SUS vai mal, vale dizer que a saúde do brasileiro também vai mal. Entretanto, como a própria pesquisa referida acima aponta para certas especificidades, é preciso analisar as condições de acesso à saúde do brasileiro(a) sob o prisma da raça, da classe e do gênero.

Sabe-se que no contexto da cisgeneridade, a falta de informação e de estrutura familiar contribuem para que mulheres de classe baixa, muitas vezes, ainda na infância e adolescência, engravidem precocemente e necessitem dos serviços de saúde pública (DUARTE; NASCIMENTO e AKERMAN, 2006).

Muitas outras, quando apresentam o desejo de interromper a gravidez, terminam se sujeitando a procedimentos clandestinos e de alto risco, uma vez que o aborto ainda é criminalizado no Brasil, exceto quando a gravidez for proveniente de um estupro, causar risco de morte à mulher ou se o feto for anencefálico.

No caso de um homem trans grávido, além de sofrer com a falta de suporte comum às mulheres cis quando optarem por não prosseguir com a gestação, estão mais sujeitos a episódios de violência física e simbólica em razão do preconceito, em meras consultas de rotina no próprio curso da gravidez.

O Programa de Saúde Materno Infantil (PSMI), criado em 1973, foi a primeira política de saúde direcionada às mulheres, que visava a garantia da saúde da mãe e do(a) filho(a) até o parto (ANDRADE, BOSI e SILVA, 2014). Até 1980, as políticas de saúde voltadas às mulheres brasileiras só consideravam um ciclo da vida das mulheres, o gravídico-puerperal, revelando uma concepção reducionista do papel da mulher na sociedade - unicamente ligado à função reprodutiva.

Em 1983, foi criado o Programa de Assistência Integral à Saúde da mulher (PAISM), o qual foi remodelado em 2004, consolidando-se como Política Nacional de Atenção Integral à Saúde da Mulher (PNAISM), dessa vez, estabelecendo uma assistência à saúde, que abrangia todas as etapas da vida da população feminina.

Após a realização de uma pesquisa qualitativa, à luz da Análise do Discurso (AD), em que foram entrevistadas 13 gestantes, maiores de idade e no segundo ou terceiro trimestre da gravidez, que utilizavam o SUS, a efetividade do direito aos serviços de assistência pré-natal envolve acesso, sensibilidade à escuta e às demandas em seus contextos psicossociais (ANDRADE, BOSI e SILVA, 2014). 
O objetivo do referido estudo foi identificar as condições de acesso e acolhimento das gestantes, na Atenção Básica, no interior do Nordeste brasileiro, desenvolvido por uma equipe de Estratégia de Saúde à Família (ESF).

É sabido que uma das maiores prioridades do PNAISM é promover atenção obstétrica e neonatal qualificada e humanizada que amplie a adesão ao Programa de Humanização no Pré-natal e Nascimento (PHPN). Os resultados da pesquisa informaram que há inúmeros óbices ao acesso à saúde, como, por exemplo, filas longas de espera para atendimento, falta de profissionais e desrespeito aos horários de funcionamento pelos funcionários, em geral.

Por outro lado, no que concerne à relação médico(a)-paciente, não houve unanimidade. Algumas gestantes relataram possuir uma boa relação com seu(a) médico(a), enfatizando como o bom diálogo desperta confiança, diferentemente das consultas em que não há uma escuta atenciosa por parte dos(as) profissionais de saúde,

Por outro lado, há uma preocupação em realizar o atendimento com celeridade em detrimento da sua qualidade, destoando do princípio da universalidade, que norteia o funcionamento do SUS, segundo o qual, a todos(as) os(as) cidadãos(as) deve ser assegurado o acesso a um atendimento humanizado pautado no acolhimento.

Ressalta-se, mais uma vez, que as limitações de acesso aos serviços de saúde, da atenção básica à alta complexidade, apresentam-se com maior intensidade, quando se trata de pacientes trans (ROCÓN et al, 2017), ainda que, o SUS contenha políticas voltadas para este público, como a Política Nacional de Saúde Integral de Lésbicas, Gays, Bissexuais, Travestis e Transexuais (LGBT) e, mais especificamente, o Processo Transexualizador do SUS, criado em 2008 e reformulado e ampliado em 2013, a população LGBT é a que menos se vê contemplada pela garantia de universalização do acesso à saúde.

Por meio de pesquisa de inspiração etnográfica e análise de documentos brasileiros de saúde e direitos humanos (ANGONESE e LAGO, 2017), foi verificada uma ausência da população trans, tanto nos discursos como nas práticas, relacionadas a direitos e saúde reprodutiva em geral, bem como sua predominante 
invisibilidade nos documentos relacionados ao processo transexualizador e aos direitos da comunidade de lésbicas, gays, bissexuais, travestis e transexuais (LGBT).

No estudo retromencionado, as pesquisadoras se utilizaram de relatos de pessoas trans, obtidos por meio de observação participante e quatro entrevistas individuais, para refletirem criticamente sobre o atendimento à saúde reprodutiva, destacando o papel dos profissionais de saúde. Dentre os temas abordados foi o aborto, situação à qual os homens trans também estão passíveis de enfrentar, ainda que essa hipótese normalmente não seja considerada devido à mentalidade heterocisnormativa no campo da saúde reprodutiva.

Em busca de referências relacionadas a direitos e à saúde reprodutiva para a população trans em documentos públicos, depararam-se com uma invisibilidade dessa população nos textos oficiais do governo brasileiro (ANGONESE e LAGO, 2017). A Política Nacional de Saúde Integral LGBT, no ímpeto de resolver o problema da discriminação e exclusão da população LGBT, previu a qualificação do SUS no que tange ao atendimento dessas categorias sociais.

No entanto, não se observa a determinação de meios objetivos de efetivação dos direitos sexuais e reprodutivos da população trans, ainda que haja referência a possibilidade de retirada do aparelho reprodutivo em homens trans, as políticas públicas são voltadas para as mulheres, não se vislumbrando a possibilidade de reprodução entre e com pessoas trans, destinando-as automaticamente a uma condição de esterilidade (ANGONESE e LAGO, 2017).

\section{PROFISSIONAIS DE SAÚDE E ACOLHIMENTO}

Todo ser humano deseja ser observado pela sua singularidade, suas especificidades que o fazem único, mas, em muitas situações, o que se deseja é ser mais um, mais uma pessoa portadora de direitos, e o acesso à saúde é uma circunstância apropriada para tornar-se um ser igual.

O profissional deve estar preparado para acolher o paciente sem criar barreiras de qualquer natureza. No caso em tela, o acolhimento às pessoas transexuais requer 
do profissional da saúde uma visão plural de gênero e da sexualidade humana para que muitas das discriminações que esse público experiencia sejam evitadas.

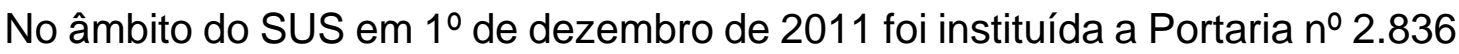
que se refere à Política Nacional de Saúde Integral de Lésbicas, Gays, Bissexuais, Travestis e Transexuais (Política Nacional de Saúde Integral LGBT). É válido ressaltar que o SUS tem como princípios a "universalidade que supõe o acesso igualitário aos serviços e ações de saúde, a equidade possibilita a concretização da justiça e a integralidade requer ações intersetoriais e uma nova governança na gestão de políticas públicas" (PAIM e SILVA, 2010).

A discriminação no acolhimento é impactante no acesso ao sistema de saúde e um dos pontos importantes é o respeito ao nome social. A Organização Mundial da Saúde (OMS) define gênero como conceitos sociais de papéis, comportamentos, atitudes e características que cada sociedade considera adequados para homens e mulheres.

Conforme os Princípios de Yogyakarta, do qual o Brasil é signatário, a identidade de gênero é a experiência interna e individual que pode ou não corresponder ao sexo atribuído no nascimento, incluindo o senso pessoal do corpo e, caberá ao indivíduo diante da sua autonomia, escolher modificar, por meios cirúrgicos ou não.

Há uma "naturalização de certas concepções e hierarquizações de gênero e raça/cor que tendem a acompanhar a atenção materna produzida, com destaque para o fato de que as mulheres grávidas que mais morrem no Brasil são mulheres negras" (MINISTÉRIO DA SAÚDE, 2014) nesse contexto, o Ministério da Saúde infere que "o corpo da mulher alvo do cuidado em saúde tende a ser naturalizado e subsumido à tríade mulher-heterossexual-mãe".

É importante lembrar que, o Ministério da Saúde através da nota técnica no 18/2014 prevê o uso do nome social no cartão SUS como direito de qualquer pessoa que se identifique enquanto transexual. O $17^{\circ}$ princípio Yogyakarta define que "toda pessoa tem o direito ao padrão mais alto alcançável de saúde física e mental, sem discriminação por motivo de orientação sexual ou identidade de gênero" e assevera que "a saúde sexual e reprodutiva é um aspecto fundamental desse direito". 
Em 2004, o PNAISM incorporou o conceito de gênero e passou a analisar questões relativas à raça, moradoras do campo e das florestas, bem como lésbicas, transexuais com objetivo de garantir redução da morbimortalidade por falta de acesso ao sistema (SILVA, ANDRADE e BOSI, 2014).

A sociedade passou por diversas transformações que nem sempre as escolas de saúde acompanharam. Nesse sentido, a Política Nacional de Educação Permanente em Saúde, apoiada na Portaria do Ministério da Saúde de no 1.996/ 2007, tem grande participação, uma vez que, o acolhimento à população transexual deve estar garantido pelo Estado através de educação permanente para que a equipe de saúde conheça as informações relacionadas aos conceitos que envolvem as questões de gênero, fluxos e a rede de atenção à pessoa trans

Além disso, a Política Nacional de Humanização, que existe desde 2003, tem como função efetivar os princípios do SUS no cotidiano das práticas de atenção e gestão, qualificando a saúde pública no Brasil e incentivando trocas solidárias entre gestores, trabalhadores e usuários. Essa política, dentre outras questões, busca o atendimento acolhedor e resolutivo, com base em critérios de risco e a garantia dos direitos dos usuários.

\section{CONSIDERAÇÕES FINAIS}

A autonomia e o poder de decisão das pessoas trans para com seus próprios corpos trazidos pelo transfeminismo, corrente do feminismo, contrasta com a medicina, que trata o corpo das pessoas trans como corpo doente, e essa dissonância de entendimentos seguramente interfere nas questões cotidiano.

A imposição do biopoder é maior do que se supõe, os discursos produzidos por essa parcela da sociedade, que encobrem preconceitos com o véu da ciência, refletindo na prática dos indivíduos.

O cuidado pode ser fortemente impactado por questões de ordem moral, de raça e gênero, produzindo práticas institucionais violentas. O não acolhimento é conhecido em diversas situações em que o julgamento moral se sobrepõe às questões éticas profissionais. 
Dessa forma, situações de abortamento e gravidez na adolescência são comumente associadas ao desrespeito e à violência. Um corpo transexual, que a sociedade já torna alvo de pressões morais, pode sofrer ainda mais. Nessa linha intelectiva, a educação permanente em saúde tem papel fundamental, uma vez que, deve efetuar relações orgânicas entre ensino, ações e serviço, assegurando adequado acolhimento.

A Educação Permanente em Saúde pode contribuir para que o trabalhador verifique, através de problematizações, quais são as falhas no serviço, a fim de que sejam sanadas, para evitar episódios de transfobia praticados por profissionais da saúde, que costumam ocorrer nos variados estabelecimentos e níveis de atenção, configurando barreiras ao acesso à saúde pela população trans.

O acesso aos serviços pela população transexual passa por circunstâncias simples, mas de alto impacto, como por exemplo a questão da mudança do nome ajustado ao gênero com o qual há identificação. Um homem trans, que esteja passando por uma gestação, pode ter dificuldade de acessar a um profissional especializado em ginecologia e obstetrícia. Sendo assim, é necessário que o sistema de informação esteja adaptado para possibilitar o seu ingresso.

A ausência de abordagem de temas relacionados à sexualidade e à diversidade sexual posiciona esses tópicos fora do conhecimento técnico, de tal forma que muitos profissionais passam a considerar que esses assuntos estariam fora do âmbito de atuação.

Além disso, dentre as medidas urgentes, estão o preparo técnico dos trabalhadores de saúde para suprir as demandas da população LGBTQIA+, a fim de gerar segurança nos indivíduos nessa relação. A preparação implicará em atendimento empático e compreensivo, com o processo educacional direcionado aos jovens especialistas, acarretando impacto na população a médio/longo prazo, sendo essencial promover instrução aos profissionais que atuam hoje na saúde. 


\section{REFERÊNCIAS}

ANDRADE, A. B. de; M. L. M., BOSI; M. Z. N. da, SILVA. Acesso e acolhimento no cuidado pré-natal à luz de experiências de gestantes na Atenção Básica. Rio de Janeiro - RJ. Saúde Debate, v. 38, n. 103, p.805-816, 2014. Disponível em: https://www.scielo.br/pdf/sdeb/v38n103/0103-1104-sdeb-38-103-0805.pdf . Acesso em: 14 nov 2020.

ANGONESE, M.; LAGO, M. C. de S. Direito e saúde reprodutiva para a população de travestis e transexuais: abjeção e esterilidade simbólica. São Paulo - SP. Saúde Soc, v. 26, n. 1, p. 256-270, 2017. Disponível em: <

https://www.scielosp.org/article/sausoc/2017.v26n1/256-270/> . Acesso em: 19 nov 2020.

Brasil. Ministério da Saúde. Humanização do parto e do nascimento / Ministério da Saúde. Universidade Estadual do Ceará. - Brasília: Ministério da Saúde, 2014. 465 p.: il. - (Cadernos Humaniza SUS; v. 4). Disponível em:

http://www.redehumanizasus.net/sites/default/files/caderno_humanizasus_v4_human izacao_parto.pdfAcesso em 28 nov. 2020.

BRASIL. Superior Tribunal de Federal. ADPF 54. Tribunal Pleno. Relator(a): Min. Marco Aurélio Julgamento: 12/04/2012 Publicação: 30/04/2013

Duarte CM, Nascimento VB, Akerman M. Gravidez na adolescência e exclusão social: análise de disparidades intra-urbanas. Rev Panam Salud Publica. 2006; n.19, v. 4., p. 236-43.

Folha informativa- Gênero. Disponível em:

https://www.paho.org/bra/index.php?option=com_content\&view=article\&id=5668:folh a-informativa-

genero\&Itemid=820\#: :text=O\%20g\%C3\%AAnero\%20se\%20refere $\% 20 \%$ C3\%A0s,e $\% 20$ rela\%C3\%A7\%C3\%B5es\%20existentes\%20entre\%20eles.\&text=As\%20normas \%2C\%20rela\%C3\%A7\%C3\%B5es\%20e\%20pap\%C3\%A9is,com\%20identidades\%2 Otransexuais\%20e\%20intersexuais. Acesso em 23 nov. 2020.

FOUCAULT, M. Microfísica do poder. Por uma genealogia do poder.

Organização e tradução de Roberto Machado. 13. Ed. Rio de Janeiro: graal.,1998.

FREITAS. André Guilherme Tavares de. O Direito à Integridade Física e sua Proteção Penal. Revista do Ministério Público do Rio de Janeiro. no 5,31-59, jan./mar. 2016.

Gomes R. Sexualidade masculina, gênero e saúde. Rio de Janeiro: Editora Fiocruz; 2008. 
HARVEY, David. 17 Contradições e o Fim do Capital. 1 ed. São Paulo, Boitempo, 2016.

INESC - INSTITUTO DE ESTUDOS SOCIOECONÔMICOS. O Brasil com baixa imunidade: balanço do orçamento geral da União 2019. Brasília: Inesc, 2020.

MARQUES, Luciana Ribeiro, LAVINAS, Gisele, Müller, Vinícius. A transexualidade e o estranhamento do corpo: sobre os recursos à mudança de sexo. Stylus Revista de Psicanálise. Rio de Janeiro n. 35 p. 133- 151 fevereiro 2018

PAIM, Jairnilson Silva; SILVA, Lígia Maria Vieira da. Universalidade, integralidade, equidade e SUS. BIS, Bol. Inst. Saúde (Impr.), São Paulo, v. 12, n.

2, ago. 2010. Disponível em

<http://periodicos.ses.sp.bvs.br/scielo.php?script=sci_arttext\&pid=S1518-

$8122010000200002 \&$ Ing $=$ pt\&nrm=iso>. acessos em 23 nov. 2020.

POLÍTICA NACIONAL DE EDUCAÇÃO PERMANENTE. Disponível em: https://bvsms.saude.gov.br/bvs/publicacoes/politica_nacional_educacao_permanent e_saude_fortalecimento.pdf. Acesso em: 15 nov. 2020.

POLÍTICA NACIONAL DE HUMANIZAÇÃO. Disponível em:

http://bvsms.saude.gov.br/bvs/publicacoes/humanizasus_2004.pdf. Acesso em: 10 nov. 2020.

PORCHAT, Patrícia; OFSIANY, Maria Caroline. Quem habita o corpo trans? Rev.

Estud. Fem., Florianópolis, v. 28, n.

1, e57698, 2020. <http://www.scielo.br/scielo.php?script=sci_arttext\&pid=S0104026X2020000100217\&lng=en\&nrm=iso >. acesso 08 nov. 2020. Epub Mai 15, 2020. https://doi.org/10.1590/1806-9584-2020v28n157698.

PORTARIA 1996/2007. Dispõe sobre as diretrizes para a implementação da Política Nacional de Educação Permanente em Saúde. Disponível em:

http://bvsms.saude.gov.br/bvs/saudelegis/gm/2007/prt1996_20_08_2007.html .

Acesso em: 11 nov. 2020.

Princípios de Yogyakarta. Disponível em:

http://www.dhnet.org.br/direitos/sos/gays/principios_de_yogyakarta.pdf. Acesso em 23 nov. 2020.

PROTECCION DE SUJETOS HUMANOS REPORTE BELMONT: PRINCIPIOS ETICOS Y DIRECTRICES PARA LA PROTECCION DE SUJETOS HUMANOS DE INVESTIGACION. Disponível em:

https://www.fhi360.org/sites/default/files/webpages/po/RETC-

$\mathrm{CR} / \mathrm{nr} /$ rdonlyres/ena7zwmzpxffu44jh4evwz55t2cm3xeg7kxwld3hjae6np2vynxn3dy5h g7tsjtaglwlkz57zxrmho/belmontSP.pdf. Acesso em 22 nov. 2020.

ROCÓN., P. C. et al. O que esperam pessoas trans do sistema único de saúde?. Interface (Botucatu) [online], v. 22, n. 64, p. 43-53, 2017. Disponível em: 
https://www.scielo.br/scielo.php?script=sci_arttext\&pid=S1414$32832018000100043 \&$ lng=pt\&tlng=pt . Acesso em: 14 nov. 2020.

SCOTT J. Gênero: uma categoria útil de análise histórica. Educação e Realidade, 1990; n.16. v.2.p. 5-22.

SILVA, Maria Zeneide Nunes da, ANDRADE, Andréa Batista de, BOSI, Maria Lúcia Magalhães. Acesso e acolhimento no cuidado pré-natal à luz de experiências de gestantes na Atenção Básica. Saúde Debate. Rio de Janeiro, v. 38, n. 103, p. 805816, Out-Dez 2014.

TAJRA, A. 7 em cada 10 brasileiros dependem do SUS para tratamento, diz IBGE. UOL, São Paulo, 04 set. 2020. Disponível em:

https://noticias.uol.com.br/saude/ultimas-noticias/redacao/2020/09/04/7-em-cada-10brasileiros-dependem-do-sus-para-tratamento-diz-ibge.htm . Acesso em: 14 nov. 2020.

Direção-Geral da Saúde. 2019. Estratégia de Saúde para as pessoas Lésbicas, Gays, Bissexuais, Trans e Intersexo - LGBTI. Lisboa: Direção-Geral da Saúde. Disponível em: <https://www.dgs.pt/documentos-e-publicacoes/estrategia-de-saudepara-as-pessoas-lesbicas-gays-bissexuais-trans-e-intersexo-Igbti.aspx> . Acesso em: 15 nov. 2020.

PINHO A. R.; RODRIGUES L.; NOGUEIRA C. (Des)construção da parentalidade

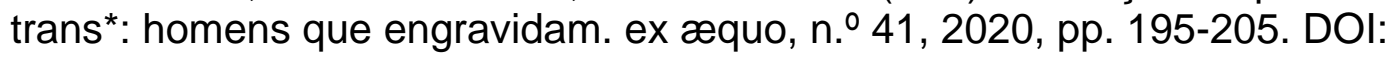
https://doi.org/10.22355/exaequo.2020.41.12. Acesso em: 15 nov. 2020. 